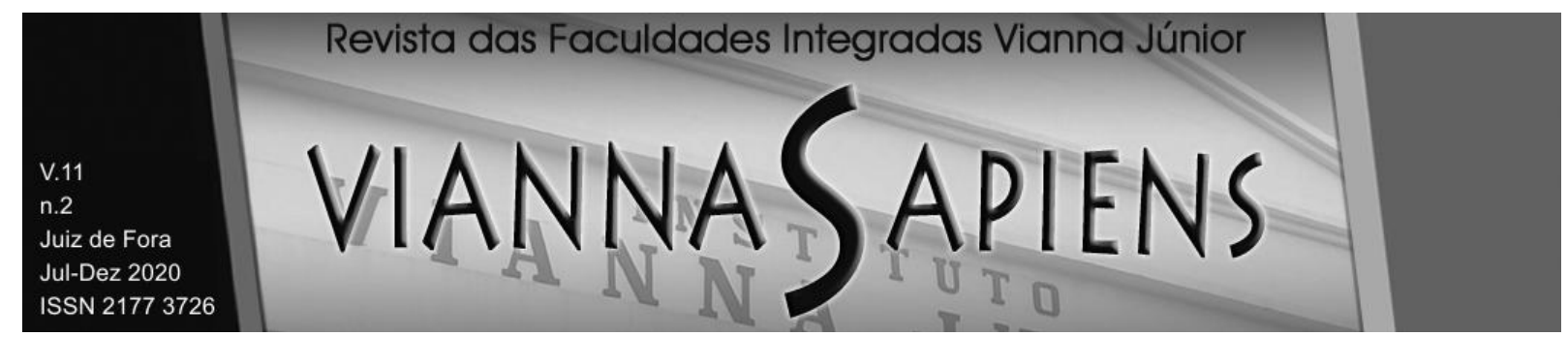

Franquias no Rio de Janeiro: um estudo sobre a viabilidade econômica de lojas de cookies a partir de um caso prático

DOI: 10.31994/rvs.v11i2.651

\author{
Paula Ignácio Pinto ${ }^{1}$ \\ Fábio Braun Silva ${ }^{2}$ \\ Celso Luiz Moreira Pieroni ${ }^{3}$ \\ Luiz da Costa Laurencel ${ }^{4}$
}

\title{
RESUMO
}

O presente artigo teve como objetivo analisar a viabilidade de implantação de uma franquia de Cookies na zona sul da cidade do Rio de Janeiro no intuito de auxiliar aqueles que têm interesse em empreender, mas possuem poucas informações sobre os fatores que norteiam a tomada de decisão referente às franquias. Para tanto, foram realizadas projeções de tempo de retorno do investimento, taxa interna de retorno e valor presente líquido no intuito de averiguar a viabilidade de implantação da respectiva franquia. O método de análise foi o estudo de caso com base nos dados disponibilizados pela empresa para análise quantitativa e qualitativa dos indicadores. Os resultados encontrados demonstraram a viabilidade do negócio levando em consideração projeções realizadas sob a perspectiva de três cenários diferentes, assim como fatores de análise mercadológica e financeira.

\footnotetext{
${ }^{1}$ Especialista em Gestão Logística pela Universidade do Estado do Rio de Janeiro - UERJ E-Mail: paula.ignaciop@hotmail.com - ORCID: 0000-0002-1203-5601

${ }^{2}$ Doutorando em Engenharia de Transportes pela COPPE / UFRJ. Professor na FAF - UERJ E-Mail: fabio.cra@gmail.com - ORCID: 0000-0002-1011-7929

${ }^{3}$ Mestre em Engenharia de Sistemas e Computação pela COPPE /UFRJ. Professor na FAF - UERJ

E-Mail: clmp2019@gmail.com - ORCID: 0000-0001-9518-0144

${ }^{4}$ Doutor em Engenharia de Produção pela COPPE / UFRJ. Professor na FAF - UERJ

E-Mail: getlc1@vm.uff.br - ORCID: 0000-0002-6167-5648
} 


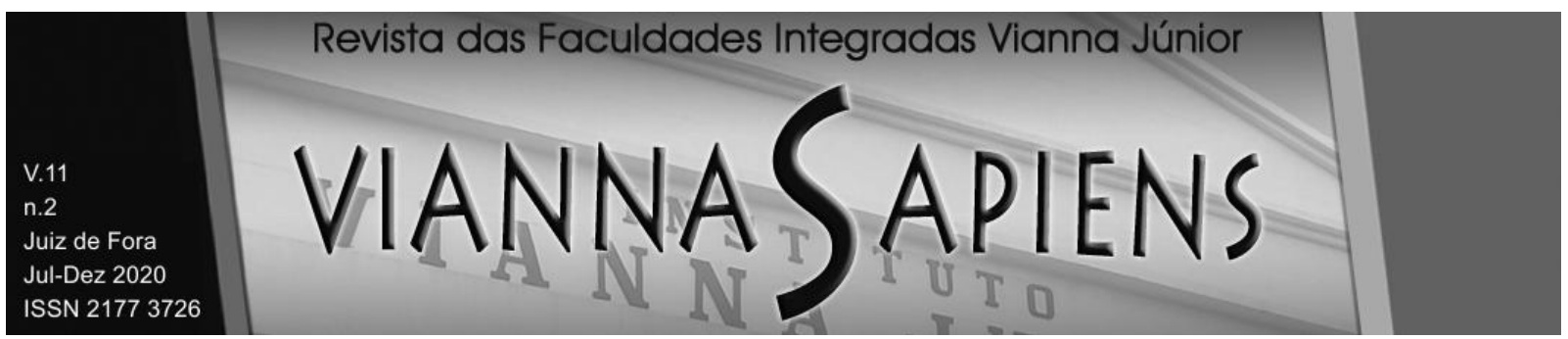

PALAVRAS-CHAVE: FRANQUIA. VIABILIDADE. ECONÔMICA. FINANCEIRA.

Franchises in Rio de Janeiro: a study on the economic viability of cookie stores from a practical case

\begin{abstract}
The purpose of this article was to analyze the feasibility of implementing a Cookies franchise in the south zone of the city of Rio de Janeiro in order to help those who are interested in undertaking, but have little information on the factors that guide the decision making regarding franchises. For this purpose, projections of return on investment, internal rate of return and net present value were made in order to ascertain the feasibility of implementing the respective franchise. The method of analysis was the case study based on the data made available by the company for quantitative and qualitative analysis of the indicators. The results found demonstrated the viability of the business taking into account projections made from the perspective of three different scenarios, as well as factors of market and financial analysis.
\end{abstract}

KEY-WORDS: FRANCHISE. VIABILITY. ECONOMICAL. FINANCIAL.

\title{
INTRODUÇÃO
}

O sistema de franquias iniciou-se pela necessidade de desenvolvimento do setor de serviços em meados do século $X X$ e na ocasião o conceito e a visão de franquia eram diferentes se comparado ao modelo atual utilizado pelas empresas. Atualmente as franquias são impulsionadas por empreendedores visionários que buscam expandir seus negócios, os chamados franqueadores, e aqueles que 


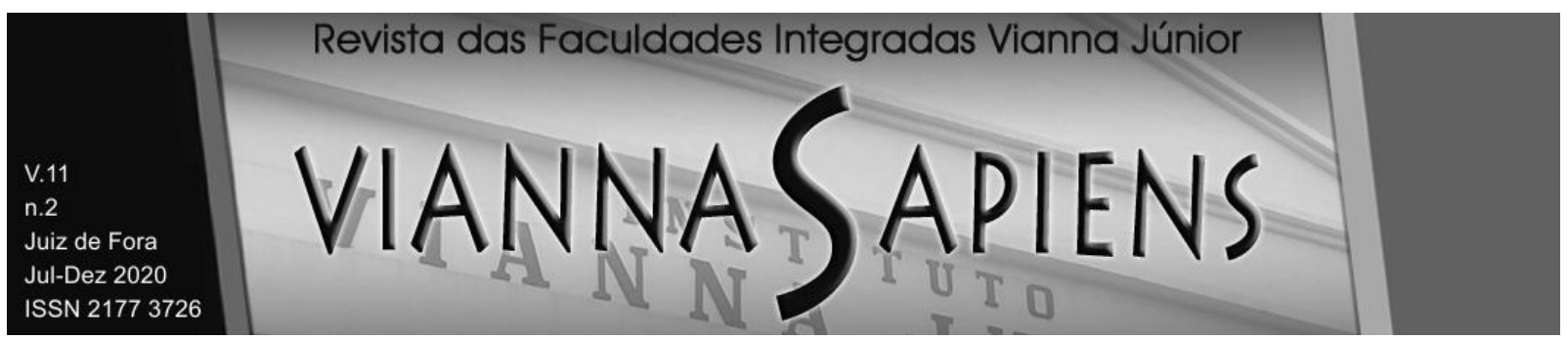

compram uma ideia já existente, buscando segurança na implantação e consolidação do negócio, que são chamados de franqueados (GIGLIOTTI, 2012).

Nesse contexto, as franquias representam um investimento interessante no qual empreendedores têm optado por investir, tendo em vista que as franquias têm se destacado na expansão da economia no Brasil apresentando um crescimento frequentemente acima do Produto Interno Bruto (VELOSO, 2016). Dessa forma, o sistema de franquias vem ganhando público nos últimos anos na cidade do Rio de Janeiro. Só no terceiro trimestre do ano de 2017, o mercado de franquias avançou $7,8 \%$, se comparado ao mesmo período de 2016 . Tal fato ocorre porque a região reaqueceu o volume de vendas nos últimos anos, principalmente nos segmentos ligados ao consumo (FREIRE, 2017).

Este trabalho teve como objetivo principal analisar a viabilidade econômica de para a implantação uma franquia alimentícia do segmento de Cookies na zona sul da cidade do Rio de Janeiro. Para tanto, foi realizado as estimativas de tempo de retorno do investimento, valor presente líquido, taxa interna de retorno com base nos dados disponibilizados de fluxo de caixa projetado para a respectiva franquia considerando três cenários diferentes. A metodologia utilizada nesse estudo foi de caráter quantitativo e qualitativo simultaneamente mediante pesquisa exploratória, documental e bibliográfica com base na abordagem conhecida como estudo de caso a partir dos dados fornecidos pela empresa para análise dos indicadores propostos na pesquisa.

Este artigo foi dividido de maneira que após essa introdução, é apresentada uma revisão da literatura sobre franquias, assim como a respeito das características do mercado e fatores de gestão inerentes ao respectivo segmento. Em seguida, foram detalhados os aspectos metodológicos da pesquisa, os resultados encontrados do estudo de caso, bem como as considerações finais decorrentes do estudo realizado. 


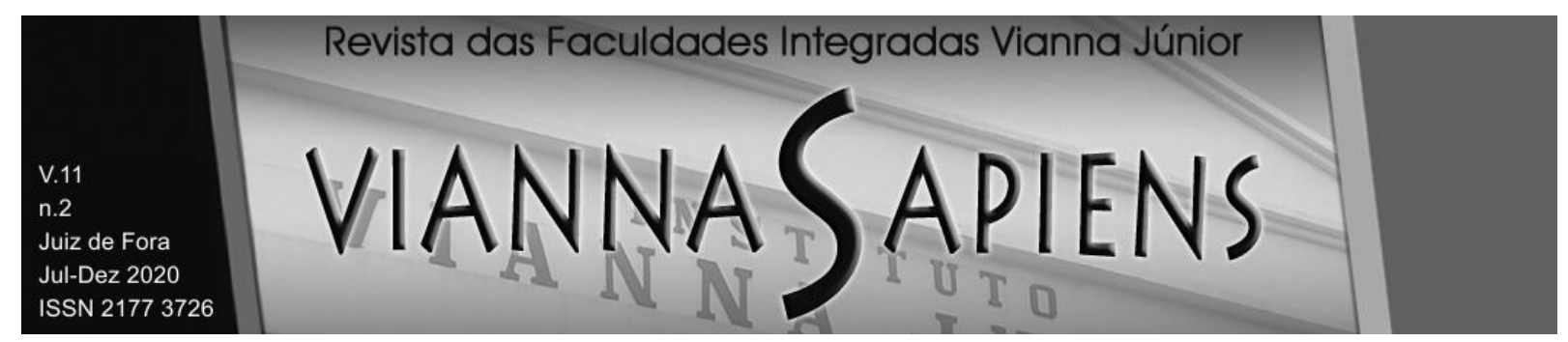

\section{REFERENCIAL TEÓRICO}

O conceito de franquia consiste na permissão para utilização de determinada marca mediante licenciamento da mesma para o respectivo uso. Por se tratar de um empreendimento já consolidado a possibilidade para uma franquia ganhar espaço no mercado geralmente é maior, haja vista a diminuição de riscos relacionados ao empreendimento, por conta do suporte proveniente do relacionamento entre franqueador e franqueado (RIZZO, 2012).

A abertura de uma franquia deve considerar alguns pontos importantes, dentre os quais se destacam os custos, a participação de mercado, a logística de abastecimento e distribuição, a capacidade operacional, bem como os recursos humanos e financeiros. Cada um desses critérios deve ser analisado separadamente para determinar a abertura ou não do empreendimento (GIGLIOTTI, 2012).

$\mathrm{Na}$ prática o conceito de franquia pressupõe proporcionar tanto para $\circ$ franqueador quanto para $o$ franqueado ganhos que justifiquem a parceria e a expansão dos negócios. Em outras palavras, enquanto o franqueador busca ampliar a região de influência, divulgando a marca no intuito de obter novos clientes, o franqueado pode focar nas atividades táticas e operacionais tendo a perspectiva de aumentar os lucros e facilitar a administração do empreendimento (RIBEIRO, 2018).

O sistema de franquias no Brasil tem crescido e se adaptado de maneira relevante desde o seu surgimento, de modo é possível constatar uma expansão rápida e consistente desse modelo de negócios. Levando em consideração o quantitativo de unidades franqueadas do setor pesquisado, o número saltou de 56.564 em 2003 para 147.539 em setembro de 2017, sendo o quarto país com o maior quantitativo de redes de franquias no mundo (FREIRE, 2017).

Entre as maiores redes de franquias no Brasil destacam-se empresas de diferentes segmentos, tais como: O Boticário, Colchão Ortobom, Kumon, AM PM Mini Market, McDonald's, Cacau Show, L'Acqua di Fiori, Wizard Idiomas, Subway e Escolas Fisk. Já as empresas que mais crescem são iGui, Poderoso Timão, D'Pil, Casa do Sorvete Jundiá, Pinkbiju, Zets, Castilho Segurança Eletrônica, Pet Cursos, Havaianas, Doutor Faz Tudo. Cabe mencionar que dentre as franquias mais 
procuradas nos últimos tempos se destacam: Habibs, Casa do Pão de Queijo, Outback, Yogoberry, Icegurt, Correios, Microlins, Kumon, Havaianas, Melissa, Hering e Home Angels, o que possibilita inferir que as franquias mais populares encontramse no setor alimentício, seguido pelo segmento de serviços e pelo setor de produção, de modo que as franquias mencionadas são as que em geral apresentam menor risco quando comparadas com as demais. (BITTENCOURT, 2011).

Considerando a abertura de franquias no ramo alimentício no Brasil, o investidor deve ficar atento a alguns detalhes relevantes para manter o bom andamento dos negócios. Entre os fatores que podem impactar a empresa, sobretudo no momento inicial do empreendimento da franquia, a comunicação, a atenção às boas práticas de fabricação na cozinha, a produção e distribuição, o aluguel do local e a localização do empreendimento, representam questões preponderante para a consolidação da nova franquia (HEITZMAN, 2017).

Apesar da mortalidade das franquias serem consideradas as mais baixas em relação a outros negócios, com o percentual de 23\% para negócios independentes contrapondo um percentual 3\% para franquias, os últimos anos foram difíceis para o segmento. De fato, a primeira queda nos indicadores foi em 2016 quando o número de marcas caiu em 1,1\%. No ano seguinte houve mais uma redução de $6,4 \%$, na qual 228 marcas deixaram de atuar como franquias no Brasil. Dessa forma, no final de 2017 o sistema de franquias teve uma diminuição significativa de demanda reduzindo o número de redes existentes (ALVARENGA, 2018).

Nesse contexto, um estudo realizado no ano de 2018 avaliou os principais motivos para o fechamento de uma franquia. Foi constatado que em primeiro lugar estava o fator localização com um percentual de 31\% nas ocorrências. Em segundo lugar destacou-se a falta de capital de giro indicando $28 \%$ das lojas fechadas, apesar da possibilidade de linhas de crédito ofertadas pelos bancos. Já em terceiro lugar foi relatado ausência de treinamento, concorrência e sazonalidade da demanda, de modo que foi enfatizada a relevância da estratégia de precificação e da análise dos indicadores financeiros (SAMMY, 2018).

Ademais, antes de iniciar a negociação de uma franquia, tanto o franqueador quanto o franqueado devem conhecer com detalhes seus direitos e obrigações na 


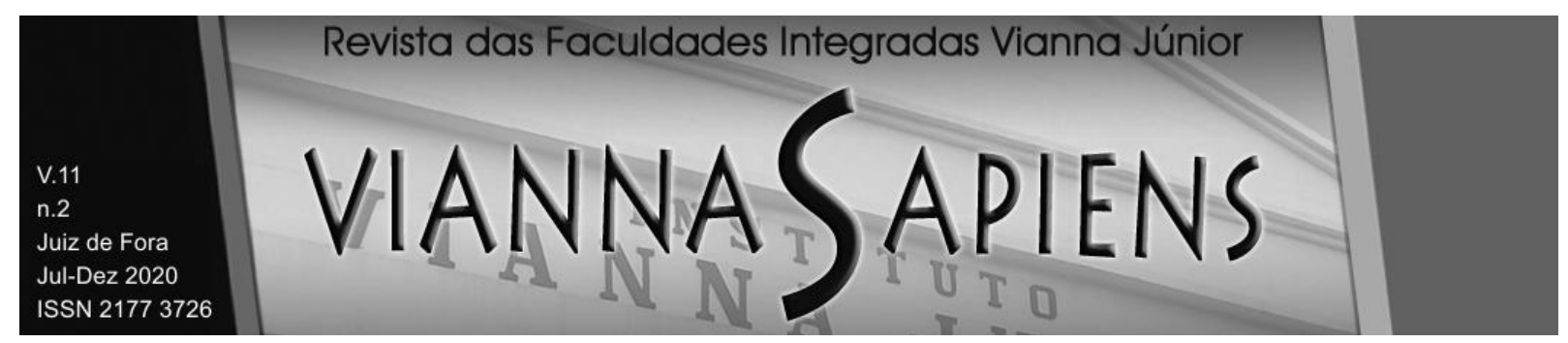

relação contratual. Os primeiros aspectos a serem discutidos são os custos para aquisição, a manutenção da estrutura administrativa, taxa de royalties e tempo de retorno, levando em consideração o valor que o empreendedor investirá no processo de compra e venda do futuro negócio. Esse valor pode ser entendido como a diferença entre os benefícios recebidos e os esforços realizados, ou seja, a diferença entre benefício e custo percebido pelo cliente numa troca (TELLES; et al., 2009).

Outro aspecto importante são os riscos inerentes à tomada de decisão a respeito da viabilidade de abertura de uma franquia, de modo que se faz necessário levar em consideração o suporte que o franqueador disponibilizará ao franqueado, tais como: manual de processos e procedimentos, know-how sobre as operações, bem como o recrutamento, o treinamento, e a consultoria de campo, sobretudo no momento de implantação do negócio (SILVA et al, 2014).

É importante destacar que com o crescimento do sistema de franquias no Brasil, houve a necessidade de uma Legislação específica a fim de regulamentar este segmento, sendo então criada a Lei no 8955/94 que está em vigor desde 1995 e segue o modelo da Lei americana disclosure statute. A referida legislação teve como objetivo servir de base para obtenção de informações sobre as obrigações do franqueado durante a negociação do empreendimento com o franqueador. No entanto, esta lei não contempla a regulação do contrato franqueador/franqueado após a assinatura do mesmo, haja vista já existirem dispositivos previstos na legislação a respeito das relações empresariais (FERNANDES, 2017).

$\mathrm{Na}$ verdade, essa legislação diminuiu significativamente problemas a respeito da abertura de uma franquia, tanto para o franqueado como para o franqueador. Existiam dificuldades pela falta de informação desde o início da aquisição do negócio até o fechamento do mesmo, o que acarretava maior desistência no processo. Ademais, mesmo se o negócio fosse desfeito o processo ainda se estendia com dificuldades pelas incertezas sobre o que foi acordado, sobretudo valores e prazos concedidos, resultando na maioria das vezes em litígios jurídicos para resolver questões contratuais divergentes (NOGUEIRA; SILVA, 2016).

Em outras palavras, antes da abertura da franquia existem alguns passos que devem ser seguidos desde o interesse pela franquia até a inauguração da loja. $O$ 
primeiro contato geralmente é feito online através de um cadastro pelo site da rede. Caso a marca tenha interesse e aprove o perfil do interessado, haverá uma reunião para apresentar a COF (Circular de Oferta da Franquia), na qual deve aparecer o balanço patrimonial do franqueador dos últimos dois exercícios, valores a serem pagos pela franquia, condições de treinamento e suporte oferecido, se há obrigação de comprar apenas de fornecedores aprovados pela rede e se existem pendências judiciais, além de nome, telefone de franqueados e de ex-franqueados que se tenham se desligado no período de até 12 meses (ZUINI; JULIO, 2016).

Após esse contato inicial é muito importante realizar visitações em diferentes lojas da rede e verificar o ambiente, o funcionamento e principalmente a opinião dos clientes a respeito do serviço. Além disso, é interessante conversar com alguns franqueados para saber a percepção dos mesmos sobre como é o cotidiano e como o franqueador se relaciona com o franqueado (SCHERER, 2016).

De maneira geral, quem busca uma franquia como alternativa de renda pensa primeiramente nos custos, tanto os fixos como os custos variáveis. Nos custos fixos está incluso o valor da manutenção da estrutura administrativa, válidos tanto para o franqueador quanto para o franqueado. Além desses custos fixos, existem os custos variáveis da franquia que são extremamente importantes para que a parceria seja proveitosa para ambos (AREND, 2010).

Sob essa perspectiva, é possível constatar que haverá momentos em que as metas dos franqueadores e dos franqueados se tornarão conflitantes, tendo em vista os diferentes interesses no que tange à implantação, consolidação e expansão do empreendimento. De fato, quando a rentabilidade não está dentro das expectativas do franqueado que por sua vez tem que arcar com custos fixos significativos como o uso da marca, locação do espaço físico, funcionários, materiais e mercadorias, essas possíveis divergências podem se acentuar em função dos objetivos discrepantes entre os parceiros comerciais (VANCE et al, 2008).

Dentre os custos fixos do franqueado pode-se mencionar a taxa de franquia que varia de acordo com cada estabelecimento conforme negociado em contrato, cobrindo investimentos como: divulgação de oferta, busca de interessados no negócio, suporte a novos franqueados, capacitação da nova equipe, orientação para 
divulgação inicial e despesas de viagens de integrantes da empresa até a localização das franquias para possível evento de abertura. No entanto, para que as diferentes despesas sejam pagas confortavelmente, as receitas aferidas devem ser compatíveis com os gastos realizados (BRITO et al, 2013).

Dessa forma, ao analisar os aspectos de implantação e manutenção da franquia, os maiores riscos normalmente estão relacionados ao retorno financeiro. Em outras palavras, se os lucros projetados forem promissores ao investidor, 0 empreendimento tende a se tornar viável e os pontos favoráveis à abertura da franquia ficam em evidência. Contudo, caso o valor do investimento seja elevado é importante avaliar a possibilidade do empreendimento se pagar no menor prazo possível tomando como base os indicadores econômicos disponíveis (RIBAS, 2006).

Nesse contexto, o Rio de Janeiro ocupa um lugar de destaque no que diz respeito ao impulsionamento da economia do país, tendo um número significativo de empresas de diferentes segmentos operando. O comércio cresce e impulsiona as vendas e faz a economia local se expandir, assim como o turismo colabora para a manutenção e expansão de restaurantes, cafés e docerias. Assim, as franquias representam uma opção interessante de investimento na cidade do Rio de janeiro, sendo a segunda do Brasil com o maior número de franquias (BRILHANTE 2017).

Outro aspecto importante que demonstra o potencial da cidade do Rio de Janeiro é a participação das redes de franquias por segmento. As franquias do segmento de alimentação aparecem com folga em 1ำ lugar com um percentual de $35 \%$ das redes na cidade, seguida pelo segmento de saúde, beleza, bem estar e de serviços educacionais que apresentam uma significativa participação de mercado na capital do estado (ABF, 2018).

Vale ressaltar que as economias de escala geradas pelo sistema de franquias são importantes fatores de vantagem competitiva em relação a negócios independentes. Esse ganho de escala traz benefícios não somente junto aos fornecedores, mas também na aquisição de pontos comerciais, na locação de espaços nas mídias, assim como no reconhecimento da marca (MOIA et al, 2013). 


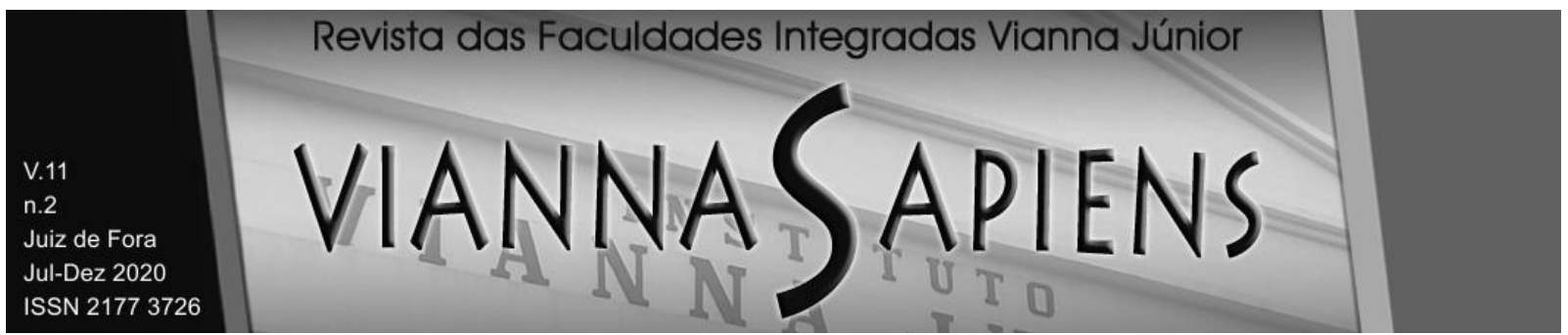

\section{METODOLOGIA}

Este trabalho trata-se de um estudo de caso sobre a franquia intitulada "Cookies" com base em estudos de viabilidade econômica com o auxílio do software "Excel", através das estimativas de fluxo de caixa, da análise de investimento pelo valor presente líquido "VPL" e pelo método da taxa interna de retorno "TIR", assim como mediante o cálculo do tempo de retorno do investimento realizado, também conhecido como Payback "PB".

O estudo de caso é caracterizado pelo estudo profundo e exaustivo de um ou de poucos objetos, de maneira a permitir o seu conhecimento amplo e detalhado, tarefa praticamente impossível mediante os outros tipos de delineamentos considerados (GIL, 2008).

O Valor Presente Líquido é o cálculo do impacto dos eventos futuros a um investimento no valor presente. Ou seja, mede o valor do fluxo de caixa ao longo do tempo (SAMANEZ, 2009).

Considerando que para o investimento ser considerado economicamente rentável, ou seja, interessante aos investidores, o VPL deve ser maior do que zero. Isso significa que a rentabilidade do dinheiro colocado no negócio no momento zero deve ser suficiente não só para pagar o próprio investimento, mas também para trazer lucros ao investidor.

Nesse sentido, ao tratarmos de uma franquia cujo valor de instalação para início de operação é estabelecido pelo franqueador, o investidor espera que sua rentabilidade seja superior a investimentos livre de risco. Assim, deve o investidor estabelecer um período razoável de tempo e uma taxa de retorno que lhe interesse. Estabelecidas essas premissas, pode enfim o investidor calcular o VPL do empreendimento.

Para encontrar o VPL, utiliza-se a equação 1:

$$
\mathrm{VPL}=-\mathrm{I}+\sum_{\mathrm{t}=1}^{\mathrm{n}} \frac{\mathrm{FC}_{\mathrm{t}}}{(1+\mathrm{K})^{\mathrm{t}}}
$$




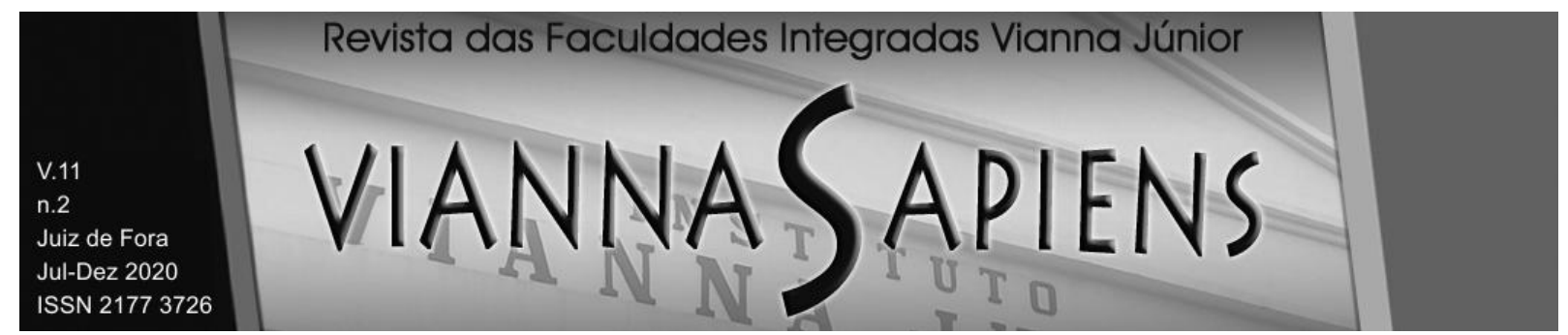

Onde:

$\mathrm{I}=$ investimento inicial

$\Sigma$ = somatória da data 1 até a data $\mathrm{n}$

FCt = fluxo de caixa no tempo estipulado

$\mathrm{K}=$ custo do capital

Para VPL > 0 ser viável.

Já o método da "Taxa interna de Retorno" segundo Samanez (2009), é a taxa que anula o VPL de um fluxo de caixa, com o objetivo de encontrar o retorno do investimento. Dado por:

$$
\mathrm{VPL}=-\mathrm{I}+\sum_{\mathrm{t}=1}^{\mathrm{n}} \frac{\mathrm{FC}_{\mathrm{t}}}{\left(1+\mathrm{i}^{*}\right)^{\mathrm{t}}}=0
$$

Onde:

I = investimento inicial

$\Sigma=$ somatória da data 1 até a data $n$

FCt $=$ fluxo de caixa no tempo estipulado

$\mathrm{i}$ = método da taxa interna de retorno

Esse cálculo permite analisar o valor do dinheiro no tempo, ou seja, quanto ele está rendendo quando investido em um empreendimento. Para o caso da loja de cookies, esse cálculo resulta no percentual de rentabilidade do negócio, ou seja, caso o percentual seja negativo no longo prazo, o dinheiro não está sendo bem investido e, portanto, poderia estar aplicado de outra maneira.

Por fim, o Payback descontado é basicamente a determinação do tempo para que o fluxo de caixa se iguale ao investimento inicial, ou seja, o período de recuperação do montante investido, sendo viável à medida que o tempo de retorno é menor do que um período-limite determinado (BREALEY, et al., 2013). Dado por: 


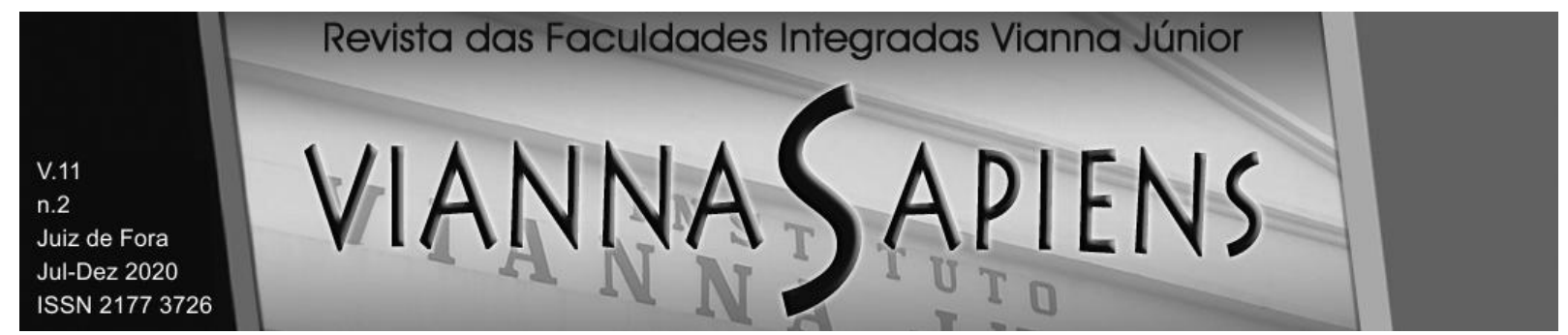

(3)

$$
I=\sum_{t=1}^{T} \frac{F_{t}}{(1+K)^{t}}
$$

Onde:

I = investimento inicial

$\Sigma$ = somatória da data 1 até a data $\mathrm{T}$

FCt $=$ fluxo de caixa no tempo estipulado

$\mathrm{K}=$ custo do capital

Para um negócio, esse pode ser considerado o resultado mais esperado para o investidor. Esse valor mostra em quanto tempo o dinheiro irá retornar. Dificilmente um franqueador consegue acertar precisamente o tempo de retorno do investimento e por isso, usa prazos padrões de acordo com o valor inicial de investimento.

Para esse caso em específico, a rede informa um prazo de aproximadamente 36 meses para o investidor receber o dinheiro investido, sem considerar os custos específicos de cada loja, usando valores médios para cálculo. Ao final da análise, será possível ver se esse prazo está de acordo ou não.

\section{LIMITAÇÕES DA PESQUISA}

Para realização do estudo de viabilidade da franquia seria muito importante realizar uma análise aprofundada em diversas lojas franqueadas para buscar informações de produtos de maior demanda, horários de maior movimento, dias de pico, pontos fortes, dificuldades e particularidades de cada loja.

Como o tempo para realização da enquete foi mais curto que o necessário e os dados deveriam ser coletados em 04 estabelecimentos de mesmo padrão da loja em estudo, para obter resultados válidos foi considerado mais adequado trabalhar com informações médias dadas pela loja da cidade do Rio de Janeiro projetando 03 cenários possíveis: "Cenário Base", "Cenário Pessimista" e "Cenário Otimista”. 


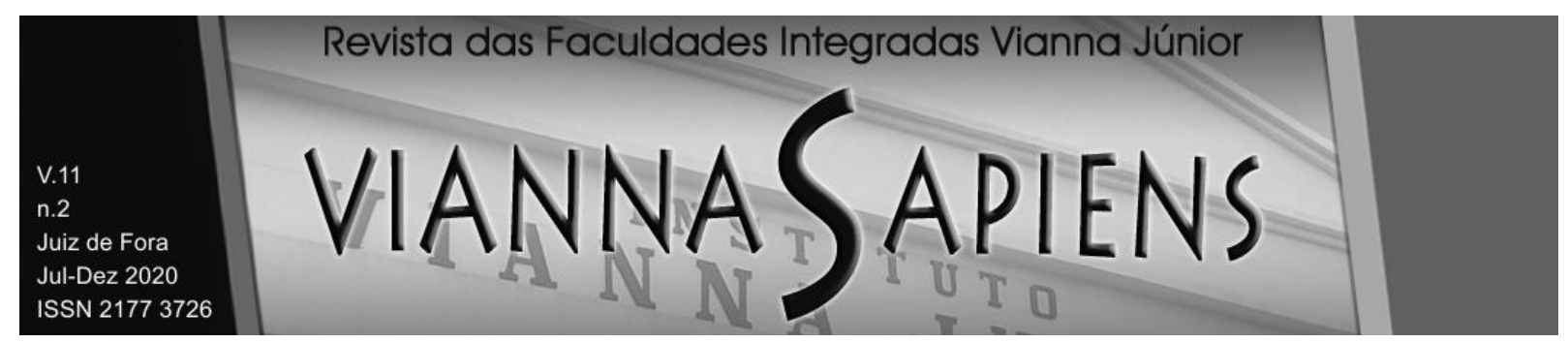

Por isso o estudo não contemplou cenários prospectivos implementados. Contudo, mesmo sem essa análise foi possível encontrar uma resposta para a implantação ou não de uma loja na zona sul da cidade, além de demonstrar quais as responsabilidades antes da abertura da franquia.

\section{RESUltados}

Através da análise mercadológica e financeira pode-se concluir que há viabilidade do empreendimento de cookies. Este investimento considerou a localização, os investimentos, custos e o funcionamento da loja franqueada, segundo os dados fornecidos pela franqueadora e previsões para os 04 anos subsequentes.

Com base nos resultados encontrados ficou determinado a implementação de uma loja de $30 \mathrm{~m}^{2}$, aberta 30 dias por mês, 12 horas por dia, com 5 funcionários em função rotativa, balcão, caixa e cozinha. Um ticket médio de $R \$ 10,67$ com rotatividade aproximadamente de 15 pessoas por hora no estabelecimento, demanda essa determinada pela comparação de clientes com outras lojas do bairro onde a loja será inserida.

Toda empresa teve os respectivos custos mensais determinados e que eventualmente sofrem alguma alteração sucinta. Para os custos fixos mensais da loja, foi considerado o aluguel do espaço, $R \$ 16.000,00$, os funcionários contratados para as diversas funções representando por ano $\mathrm{R} \$ 150.000,00$, a compra de suprimentos para as receitas $R \$ 10.000,00$, eletricidade $R \$ 2.800,00$, internet $R \$ 500,00$, produtos de limpeza $R \$ 500,00$, extras $R \$ 3.000,00$, totalizando $\mathrm{R} \$ 45.000,00 /$ mensais.

Para o investimento total foi considerado o capital de giro de $R \$ 40.000,00$, estoque inicial de $R \$ 15.000,00$, taxa da franquia de $R \$ 43.000,00$, obras, civil e projeto de $R \$ 198.000,00$, equipamentos, mobiliário, informática, $R \$ 63.000,00$, estrutura, treinamento, abertura da empresa, seguro, $\mathrm{R} \$ 34.500,00$, aluguel da loja $R \$ 16.000,00$, extras $R \$ 10.000,00$. Além da taxa de royalties de $5 \%$ e taxa de marketing de $1,5 \%$, sobre o faturamento bruto. 


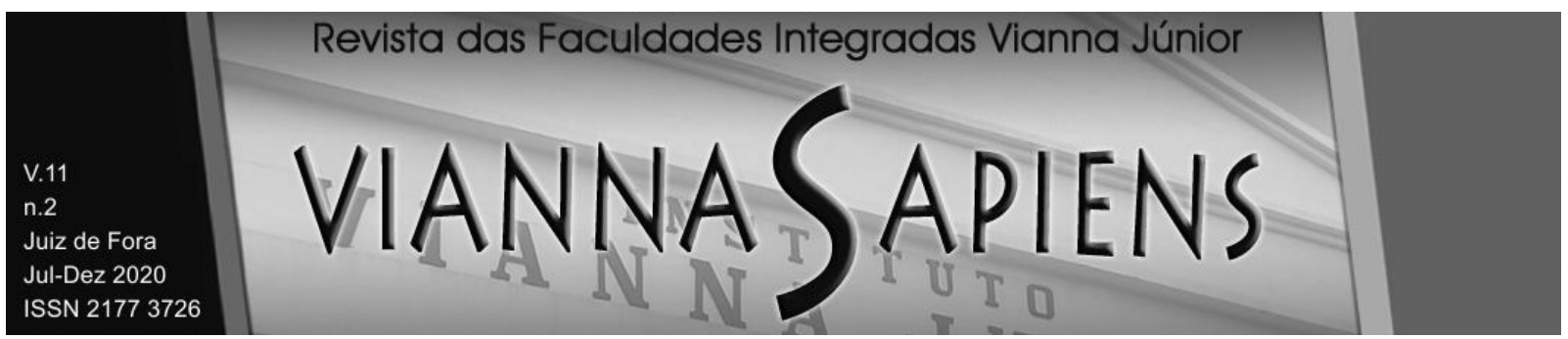

Concluiu-se, portanto, que em um cenário cujo aporte mínimo a ser realizado pelo investidor é de $R \$ 420.000,00$ para o início da operação no qual exige um retorno de $15 \%$ ao ano, podendo variar entre $12 \%$ e $25 \%$ ao ano, tendo em vista o risco corrido e baseando a análise simultaneamente nos cenários pessimista e otimista, o negócio se torna viável a partir do sexto ano de operação.

\section{Gráfico 1: Análise econômico-financeira da Franquia "Cookies"}

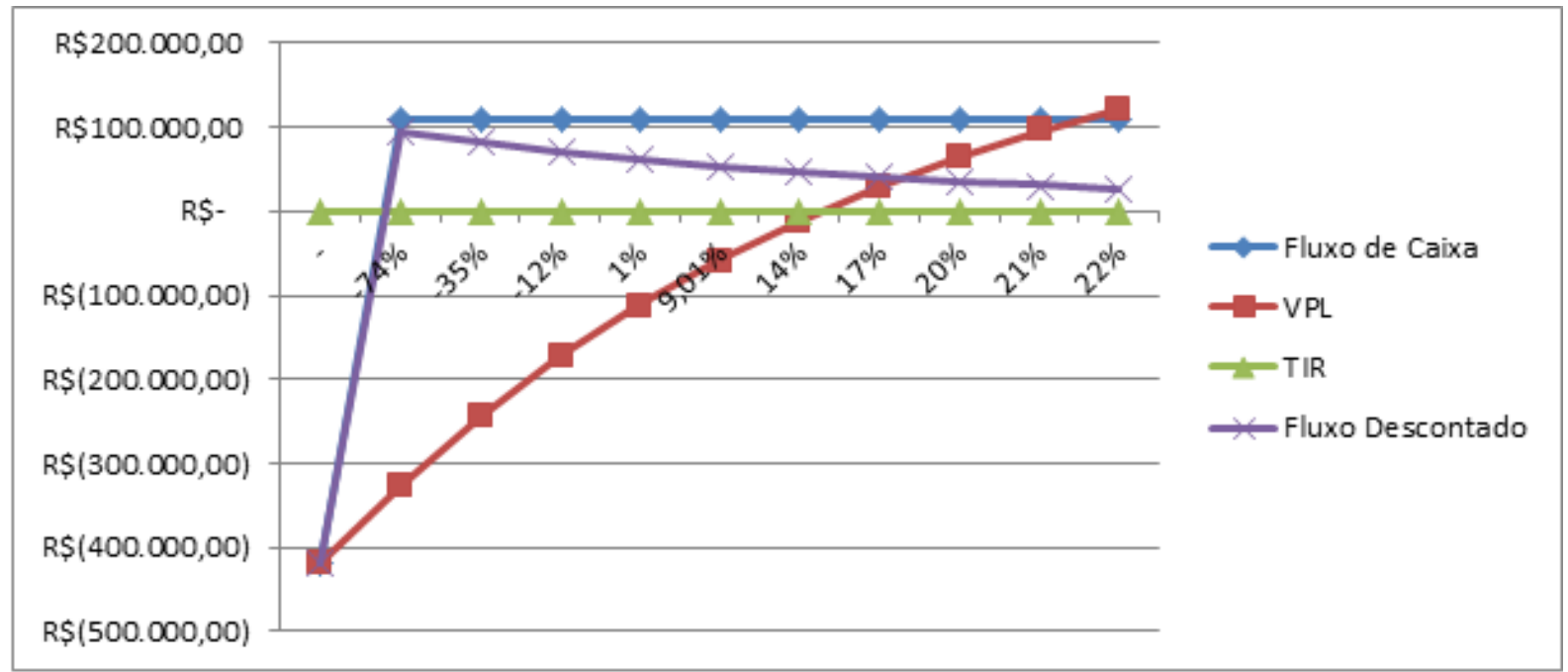

Fonte: Elaboração Própria (2018)

No gráfico é possível observar que para um fluxo de caixa constante, entrada e saída de dinheiro, tem-se um VPL crescente, iniciando com saldo negativo do valor total de investimento e com os lucros ao longo do tempo se torna positivo. Neste caso, como mostra o gráfico, a partir do ponto VPL zero, o negócio passa a lucrar tendo como base a TIR, taxa de retorno, também crescente.

Como a taxa de retorno só pode ser estimada aproximadamente, tem-se nesse caso um investimento inicialmente prejudicial ao investidor. Isso quer dizer que o dinheiro investido no negócio nesse caso estaria mais bem aplicado em outras interações financeiras, comparando a oportunidade de investimento e o mercado financeiro.

Dessa forma, no momento em que o VPL e a TIR se encontram em zero, significa que a taxa de atratividade e a taxa interna de retorno também serão zero. Em outras palavras, a partir desse ponto a franquia de cookie será lucrativa. 


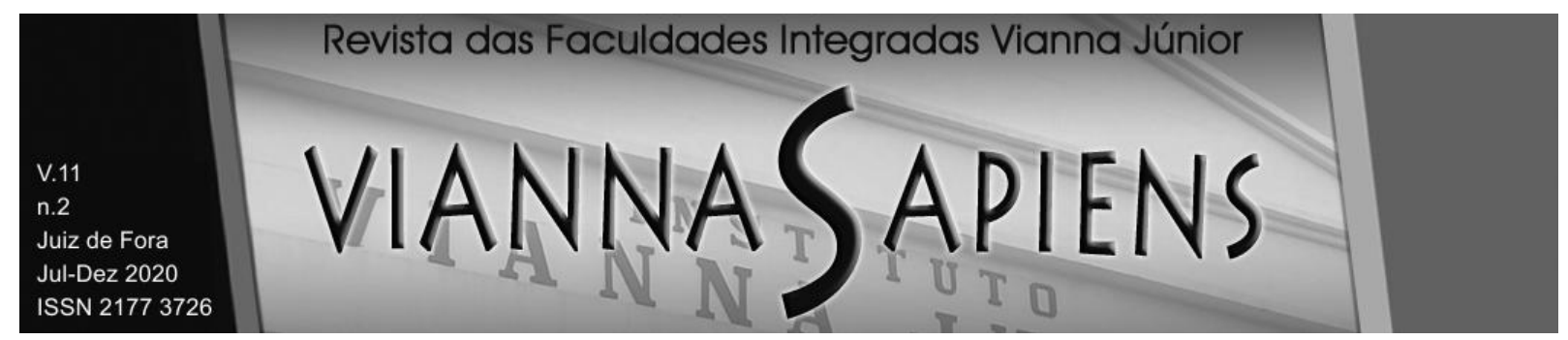

Isso se dá a partir do quarto ano no caso da franquia em questão. Porém, como essas taxas não são fixas, podem variar muito para diferentes empreendimentos, levando em consideração o momento de implementação do negócio, além do capital investido.

Por fim, com o fluxo de caixa pode-se avaliar a atratividade de uma oportunidade de investimento, fazendo cada investidor ter uma perspectiva do negócio de acordo com suas necessidades. Neste caso específico, o custo aproximado por mês é de $R \$ 45.000,00 /$ mês e lucro bruto $R \$ 58.000,00 /$ mês, em que se acredita um retorno líquido de $\mathrm{R} \$ 12.000,00 /$ mês.

No último ano mesmo com um cenário de dificuldades no Brasil a rede cresceu de modo consistente. Somente em 2016, a rede teve um faturamento de 31 milhões. No Rio de Janeiro, a primeira loja surgiu em 2016. Depois dela, mais 03 lojas foram abertas em shopping centers e 01 como loja de rua, em diferentes bairros cuidadosamente escolhidos pelo franqueado com o apoio do franqueador.

Desta forma, foi possível identificar que o bairro de Ipanema na zona sul da cidade do Rio de Janeiro, representa um bom local para a abertura de uma loja da rede, haja vista possuir uma alta circulação de pessoas, desde jovens até pessoas da terceira idade, sendo considerado um importante polo turístico. Ademais, o respectivo bairro possui somente um concorrente direto no ramo de cookies e complementos, o que reforça a decisão de introduzir uma loja do segmento no local.

\section{CONSIDERAÇÕES FINAIS}

A implantação de uma franquia normalmente requer um investimento significativo de recursos proveniente de alguma fonte de financiamento ou capital próprio, de maneira a imobilizá-lo por um período de tempo previamente determinado. Obviamente, ao término desse período espera-se que a franquia traga retorno favorável equivalente ao imobilizado inicial e lucros superiores ao que poderia ser obtido com o capital investido em outro negócio, uma vez que o objetivo 


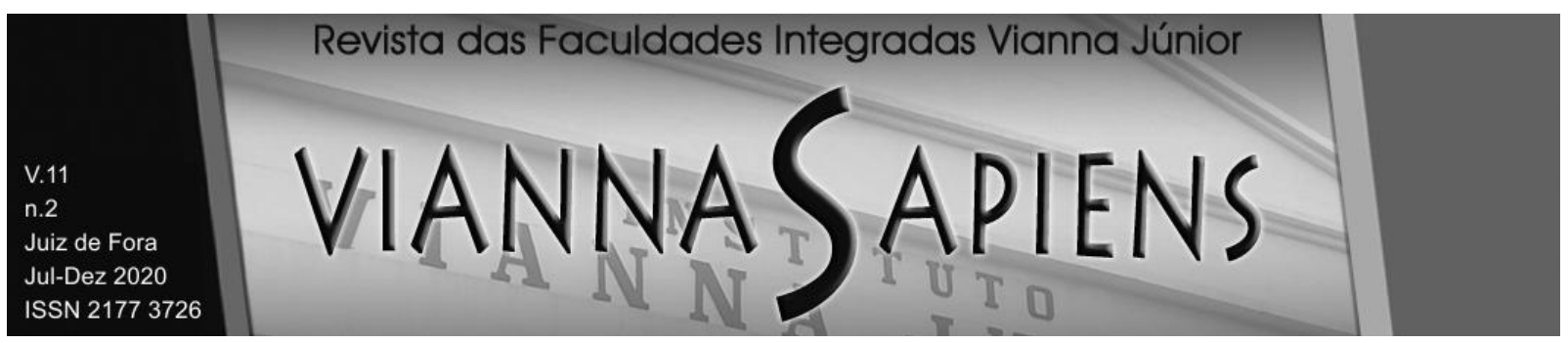

da empresa é maximizar os lucros e prestar um serviço considerado de excelência aos clientes.

Com efeito, a análise detalhada da viabilidade do investimento torna-se imprescindível, assim como as estimativas dos lucros esperados, levando em consideração os riscos do respectivo empreendimento. Dessa forma, os indicadores econômico-financeiros utilizados nessa análise foram muito importantes para orientar adequadamente o processo de tomada de decisão a respeito da aplicação ou não dos recursos no referido projeto.

Vale ressaltar que a partir da compreensão dos detalhes para a abertura de uma franquia, através do entendimento detalhado da legislação, do melhor uso da marca, das vantagens e desvantagens em se optar pelo modelo de franquias é possível adquirir conhecimento preliminar do setor, o que representa um suporte inicial para a tomada de decisão. Contudo, a decisão pela viabilidade ou não do empreendimento só deve ser consolidada a partir da análise dos indicadores financeiros, mediante a utilização e avaliação de cálculos pontuais detalhados que permitam a projeção adequada dos possíveis cenários.

Desta forma, considerou-se viável nessa análise a implantação de uma franquia do setor alimentício especializada em doces, levando em conta as características técnicas promissoras apresentadas, tais como localização, padronização, qualidade dos produtos, capacitação dos funcionários, marca, além do crescimento do mercado de franquias.

Por fim, analisando os indicadores financeiros se confirmou a viabilidade do negócio para investidores que buscam um empreendimento em longo prazo, com retorno esperado a partir do quarto ano de funcionamento do empreendimento, considerando a perspectiva do "Cenário Base" padrão. Já para o cenário pessimista a perspectiva de retorno do investimento ficou em 05 anos, enquanto que no cenário otimista foi possível encontrar um retorno do investimento projetado para 03 anos após o início das operações. Cabe destacar que para empreendedores que buscam um retorno do valor investido de maneira mais imediata a franquia se mostrou inviável, ainda que na análise realizada tenham sido considerados possíveis 


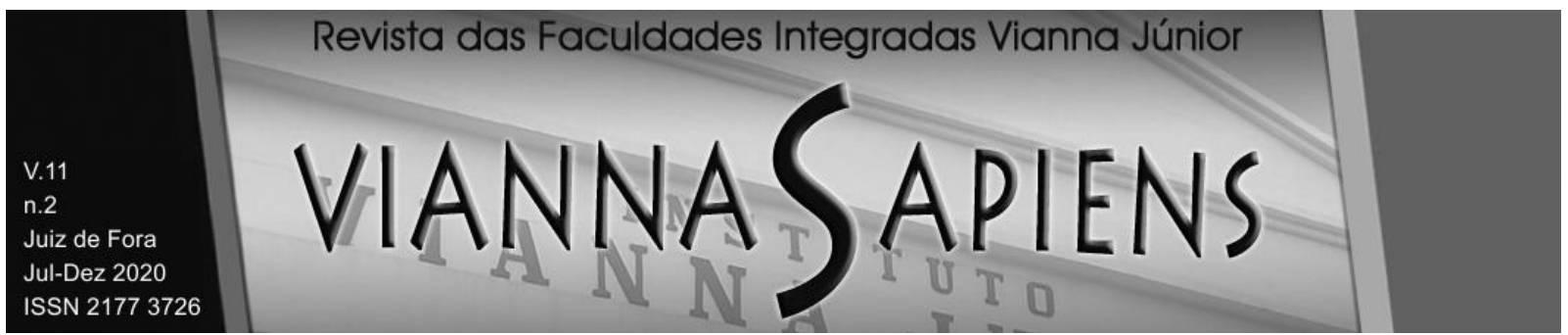

problemas com a finalidade de diminuir assim os riscos de falência de novos empreendimentos.

\section{REFERÊNCIAS}

ABF - Associação Brasileira Franchising. Perfil das $\mathbf{5 0}$ maiores franquias no Brasil: Marcas associadas, ABF 2017. Disponível em: <https://www.abf.com.br/wpcontent/uploads/2018/01/Perfil-das-50-maiores-Franquias-no-Brasil-Marcasassociadas-ABF-2017.pdf>. Acesso em: 15 de janeiro de 2018.

ALVARENGA, Darlan. Número de redes de franquias no Brasil cai pelo 20 ano seguido. Disponível em: <https://g1.globo.com/economia/pme/noticia/numero-deredes-de-franquias-no-brasil-cai-pelo-2-ano-seguido.ghtml>. Acesso em: 14 de abril de 2018.

AREND, Amanda Zart. Franquias: uma análise para decisão do melhor investimento. Universidade Federal do Rio Grande do Sul, 2010. Disponível em: $<$ https://lume.ufrgs.br/bitstream/handle/10183/29683/000778727.pdf?sequence=1\&is Allowed $=\mathrm{y}>$. Acesso em: 24 de dezembro de 2017.

BITTENCOURT, Claudia. Como funciona a cobrança de royalties. São Paulo, 2011. Disponível em: <http://exame.abril.com.br/pme/noticias/como-funciona-acobranca-de-royalties-2>. Acesso em: 24 de dezembro de 2017.

BREALEY, R. A.; MYERS, S. C.; ALLEN, F. Princípios de finanças corporativas. 10. ed. Porto Alegre, Editora AMGH, 2013.

BRILHANTE, Claudia. Em 2018, a expectativa é de crescimento de vendas. Sistema Fecomércio, 2017. Disponível em: <http://www.fecomercioce.org.br/observatorio/sem-categoria/em-2018-expectativa-e-de-crescimento-devendas/>. Acesso em: 31 de janeiro de 2018.

BRITO, Flávio Augusto P.; MARTINS, Vidigal F. Fatores que influenciam a formação do preço de venda: um estudo de caso. Rio de Janeiro, 2013. Revista Linkania, Rio de Janeiro (RJ), v. 1, n. 7, p. 86-164, jun. 2013. 


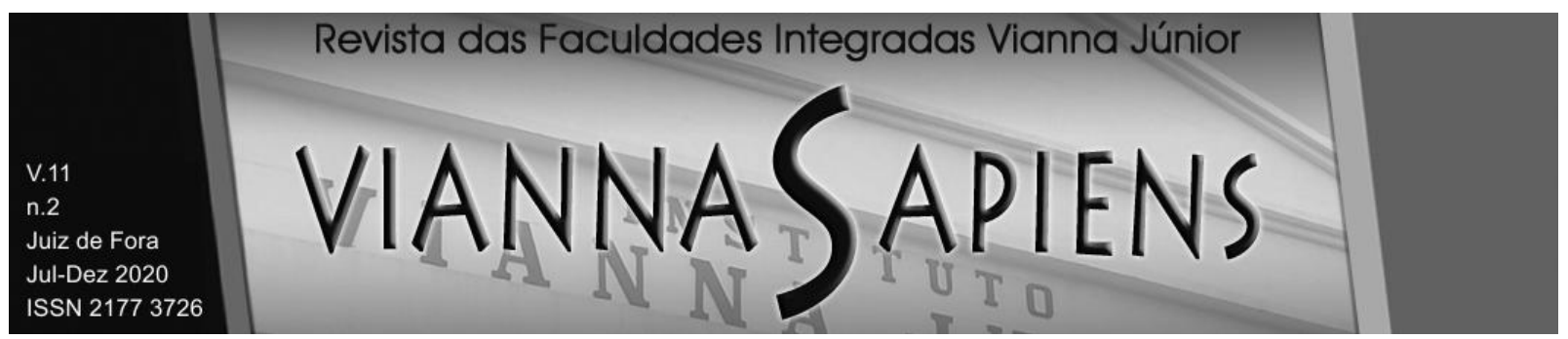

FERNANDES, Lina. Franquia: comentários à Lei n 8.955/94. Revista Jus Navigandi, ISSN 1518-4862, Teresina, ano 22, n. 5158, 15 ago. 2017. Disponível em: <https://jus.com.br/artigos/36898>. Acesso em: 24 de janeiro de 2018.

FREIRE, Debora. Mercado de franquias avança 7,8\% no 3o Trimestre de 2017, indica ABF, 2017. Disponível em: <http://www.segs.com.br/demais/88677-mercadode-franquias-avanca-7-8-no-3-tri-de-2017-indica-abf.html>. Acesso em: 15 de janeiro de 2018.

GIGLIOTTI, Batista. O funcionamento do sistema de franchising. In: MELO, P. L. R.; ANDREASSI, T. (orgs.). Franquias brasileiras: estratégia, empreendedorismo, inovação e internacionalização. São Paulo: Cengage Learning, 2012.

GIL, Antônio. Métodos e técnicas de pesquisa social. 6 ed. São Paulo, Editora Atlas, 2008.

HEITZMAN, Adam. 05 erros que as pessoas cometem ao comprar uma franquia. Revista Pequenas Empresas Grandes Negócios, 2017. Disponível em: <http://revistapegn.globo.com/Franquias/noticia/2017/04/5-erros-que-pessoascometem-ao-comprar-uma-franquia.html >. Acesso em: 24 de janeiro de 2018.

MOIA, Roberto. Logística de abastecimento: os gargalos na gestão de suprimentos de uma franquia. A Revista Eletrônica da Faculdade de Ciências Exatas e da Terra Produção/construção e tecnologia, v. 4, n. 6, 2015. São Paulo, 2013.

NOGUEIRA, Nádia Lemos; SILVA, Keuson Nilo. Apostila sobre Franquias:

Franquia, Franqueado e Franqueador. Serviço Brasileiro de Apoio às Micro e Pequenas Empresas - SEBRAE. Brasília, Distrito Federal, 2016. Disponível em: <http://www.sebrae.com.br/Sebrae/Portal\%20Sebrae/Anexos/franquias_portal_sebra e.pdf>. Acesso em: 24 de dezembro de 2017.

RIBAS, João. Por dentro de uma franquia. Rio Grande do Sul: Serviço Brasileiro de Apoio às Micro e Pequenas Empresas - SEBRAE v. 1, Editora Maneco, 2006.

RIBEIRO, Adir. A essência de uma franquia de sucesso. São Paulo, 2018.

Disponível em: <https://endeavor.org.br/a-essencia-de-uma-franquia-de-sucesso/> Acesso em: 09 de dezembro de 2017. 


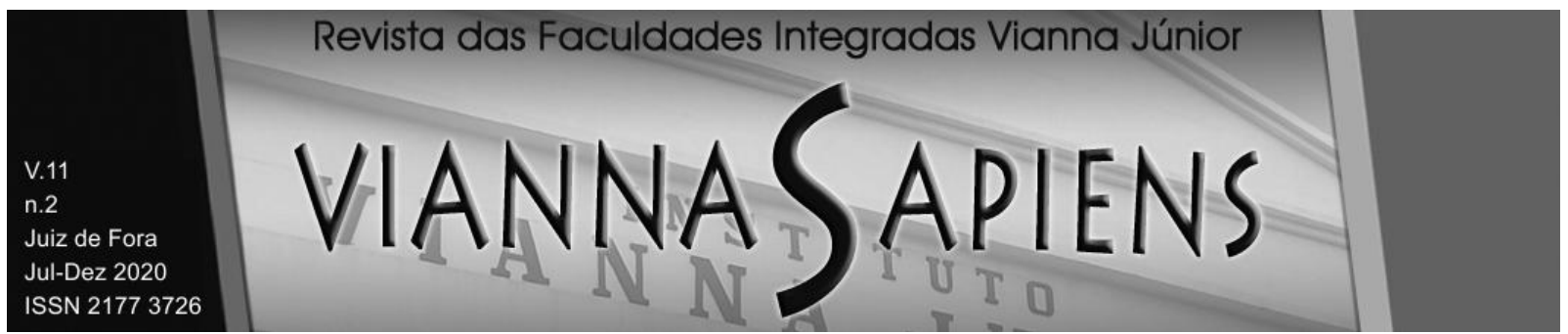

RIZZO, Marcus. Quais são as características das franquias de serviços? Revista Exame. Editora Abril, São Paulo, 2012. Disponível em:<http://exame.abril.com.br/pme/noticias/quais-as-caracteristicas-das-franquiasde-servicos>. Acesso em: 24 de dezembro de 2017.

SAMANEZ, Carlos P. Engenharia Econômica, v. 1, São Paulo: Editora Pearson, 2009.

SAMMY, Eduardo. Top 05 erros que levam ao fechamento de franquias. 2018. Disponível em: <https://www.portaldofranchising.com.br/franquias/causas-defechamento-de-franquias/>. Acesso em: 14 de abril de 2018.

SCHERER, Marcelo. 05 passos para se preparar antes de abrir uma franquia. Disponível em: <https://centraldofranqueado.com.br/blog/2016/09/06/5-passosantes-de-abrir-franquia/>. Acesso em: 14 de abril de 2018.

SILVA, Telmo J. M.; et al. Valor da relação com redes de franquias: análise comparada entre franquias convencionais e micro franquias. Revista da Micro e Pequena Empresa FACCAMP, Campinas (SP), 2014, v. 8, n. 3, p. 2-17.

TELLES, R., ROMBOLI, S. M., \& SIQUEIRA, J. P. L. Marketing de relacionamento e operação de call-center: análise comparada do posicionamento de operadoras de telefonia celular em São Paulo. Revista Brasileira de Marketing - REMark, vol. $8 \mathrm{n}$. 1, p. 112-137, 2009.

VANCE, P. S.; FÁVERO, L. P. L.; LUPPE, M. R. Franquia Empresarial: Um estudo das características do relacionamento entre franqueadores e franqueados no Brasil. Revista de Administração, São Paulo, v. 43, n. 1, p. 59-71, Jan/mar., 2008.

VELOSO, Leonardo. Franquias: entenda esse mercado em expansão. 2016. Disponível em:<http://br.blastingnews.com/economia/2016/03/franquias-entendaesse-mercado-em-expansao-00808307.html>. Acesso em: 24 de janeiro de 2018.

ZUINI, Priscila; JULIO, Rennan A. 10 Passos para abrir uma franquia. Revista Pequenos Empregos Grande Negócios. São Paulo, 2016. Disponível em: $<$ https://revistapegn.globo.com/Franquias/noticia/2016/04/10-passos-para-abrir-umafranquia.html > . Acesso em: 14 de abril de 2018. 


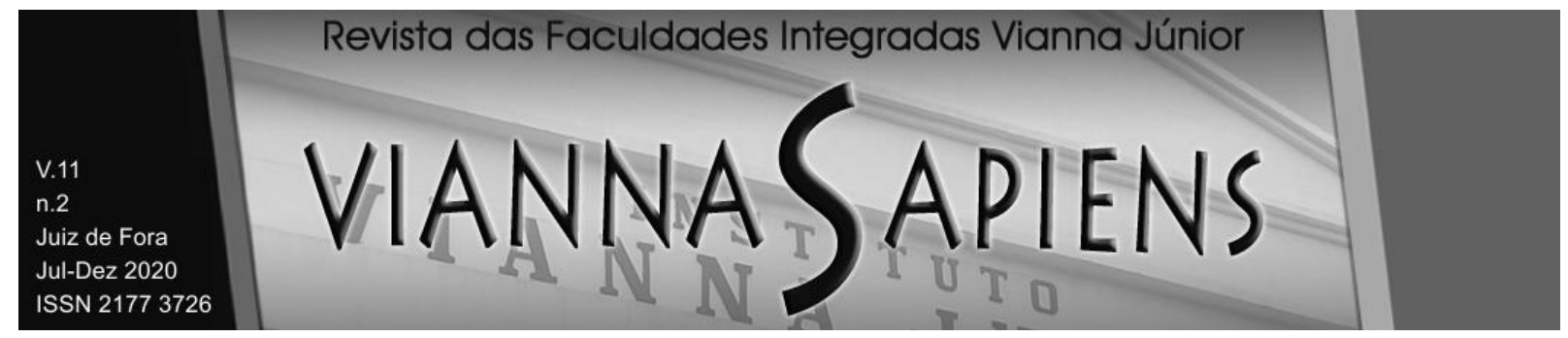

Recebido em 31/03/2020

Publicado em 31/08/2020 